\title{
The Challenges And Opportunities Of Wireless Technologies In The Classroom: Related Standards And Regulations
}

Ngozi Oriaku, Elizabeth City State University

\begin{abstract}
Wireless technologies have revolutionized the ways teaching and learning have become in many colleges and universities. It is therefore interesting to observe the way wireless technologies are used to organize small group meetings. It provides online access to internet resources such as instructor lecture series. It finally helps in problem-solving of real-time interactions with students and instructors without being present at the physical place. Through the use of journal articles, textbooks, and research findings from the World Wide Web, the paper addresses some concerns: (1) what is the advantage of using wireless devices in teaching and learning? (2) What challenges will one face using wireless devices in classroom? Is it an effective means of teaching and learning? This study therefore, focused on challenges and opportunities of wireless technologies in the classroom and assessed the availability and readiness of students and administrators.
\end{abstract}

\section{INTRODUCTION}

nstitutions of higher learning are faced with continuous strategies and innovation of technological change in educating students of today. In the early 1980s the need to purchase a personal computer for personal use or classroom learning was a difficult task to accomplish because of the high cost of personal computer to students and educators. But in recent years, the rapid decreasing price of desktop, laptop, and wireless technologies and the technical skills needed by giant corporations have caused educational institutions to re-examine the level and type of technological competences given to their students. This study focused on the challenges and opportunities of wireless technologies in the classroom at ECSU. There are availability of personal computers in computer labs and dormitories. However, educators and students are returning back to campus with high-tech wireless gadgets, ready to teach and learn from anywhere at anytime. Wireless devices meet the needs of this "new wave" of students with full-time jobs, family, and the need for flexible scheduling. Wireless technologies allow one to be anywhere and learn at anytime. This new way of learning requires faculty and other educators to fine tune their teaching styles. Faculty members must be trained in design and development of web courses and how to take advantage of Internet applications to aid in communication. The push to incorporate wireless technologies into classrooms has grown almost as fast as the new technologies are discovered. The incorporation of wireless technologies, such as, PDA's, wireless laptop computers, videoconferencing, and handheld computers, have had a profound effect on the goals of our education system. The Internet has made available vast amounts of information that was not readily available to educators and students in the past. It is no longer enough to teach students subjects, students must be given a knowledge base plus a hands-on application of that knowledge that will apply to the "real world". This change emphasizes the changing roles for the entire education system for faculty, students, and administrators.

The purpose of the paper is to examine the challenges and opportunities of wireless technologies and to answer two crucial questions such as (a) what are the availability and readiness of student body to accept wireless technologies in classroom? (b) What tools and training are necessary to incorporate wireless devices into the classrooms? (c) What are the related regulations and standards? 


\section{REVIEW OF LITERATURE}

There seems to be an acceptable norm in today's environment regarding the value of wireless technologies in sharing data and information among educators, students, and administrators. Wireless technologies can allow students, teachers, and administrators to talk to one another at anytime from anywhere they may be. Educators need to begin to see it as normal that they can access information, record their lecture series and ideas with one device, and that they can share these lectures and ideas with their students and colleagues. Walery Darrell (2007) describes that the availability of wireless technologies leads to new and better uses for laptops and other devices. It allows teachers to do more lesson planning and administrative tasks outside their classrooms in other parts of the building. It gives them the ability to move a laptop around a classroom to take notes on student project. Matt Hamblen (2000) says that when a company's hub instantly returned signal from another firm due to the factory defaults on its wireless hub that company is inviting hackers and intruders into the company's system. He further stresses that wireless LANs can be easily accessed by neighbors friendly or not. He indicates that information technology managers should provide robust security by making sure that wireless users are authenticated, preferably with a user name and password as well as a token. He also mentioned that encryption should be used end-to-end in a connection. Wesley Fryer indicated that wireless technologies will become more prevalent within homes, businesses, and classrooms. Glen and Gina Bull, Joe Garofalo, and Judi Harris predicted the era of ubiquitous wireless technologies in classrooms across America. Like the PDA and other types of wireless in the hands of college students today, costing about $\$ 120$ to $\$ 800$ each. Sande Mark, (2004) indicates that wireless infrastructure today is more affordable than it was at its outset. Access points are now a few hundred dollars of about $\$ 150$ and no longer require expensive to install power connections. She stresses that large campuses can often install a broad coverage WiFi network for under $\$ 500,000$, with a life cycle replacement cost of about $\$ 140,000$ per year with a three year replacement cycle. She further indicates that smaller campuses can get by for much less. Wireless technologies connect to the Internet will upload email messages and download assignment papers. etc. This prediction is not far fetched, although some campuses are lacking the use of wireless technologies in learning and teaching. The level of "true" technology integration in classrooms across higher institutions in America is absolutely poor.

The challenges to adapt to wireless technologies by educators and students, however, is one of understanding and exploring these resources to support teaching and learning. One question comes to mind, what tools, capabilities, and training will be necessary to develop mobile applications? The growth in wireless technologies presents university officials with a range of challenges. For instance, end users place greater demands on the capacity and ability of Wi-Fi, the hubs that send data between a campus network and the Internet and the laptops equipped with Wi-Fi network cards. The most challenging problem facing higher education systems incorporating wireless devices into their classrooms is technical support. Schools must have an in-house support or outsourcing the support for the effective use of the wireless devices. If wireless technologies are incorporated into the classrooms the users of that technology must have full confidence, not only on the technology, but also, the support for the technology. In order to gain support for the use of wireless technologies in the classroom technical support and assistance is critical. Major challenges of wireless technologies is that many campuses do not have the resources to provide their faculty and students with the tools necessary to use the emerging technology to its fullest potential. While some campuses may have money to buy updated computers, they may not be able to afford the new and updated software. Many factors do affect the implementation of wireless technologies in classrooms such as electromagnetic interference and physical obstacles that limit coverage of wireless networks. In addition to coverage, data security and standards are major obstacles of wireless networks deployment. The existence of multiple standards of wireless technologies such as $802.11 \mathrm{~b}$ known as "Wi-Fi," the most widely used local area network standard in the mid-2002, Wi-Fi is a radio based protocol using $2.4 \mathrm{GHz}$ band of the radio spectrum as microwave ovens, wireless phones and other wireless devices which interfere with these networks. Joel Conver expresses that $802.11 \mathrm{~b}$ is the standard used by Apple computer for its airport cards and airport base stations. He indicated that the range is 150 to 300 feet and that it is a wireless networking alternative to fixed Ethernet, and transmission speeds is up to 11 megabits per second(Mbps) unlike Ethernet connection of $10 \mathrm{Mbps}$. The 802.11a is another standard with a high $5 \mathrm{GHz}$ radio band that allows transmission speeds of up to $54 \mathrm{Mbps}$. Because of its higher frequency there are fewer interference for 802.11a networks. Literature indicated that fewer products are currently available for this standard and not compatible with $802.11 \mathrm{~b}$ networks. Bob Liu emphasized that $802.11 \mathrm{~g}$ 
standard operates in the same frequency band but faster than $802.11 \mathrm{~b}$ and some analysts predicted that it could become the next broadly accepted wireless standard. Bluetooth is another wireless standard that has gained broad acceptance and support, and allows direct communication between portable digital devices and computers without an access point. Rick Merritt says that Bluetooth has a shorter range and can transfer data at 720 kilobits per second (0.72Mbps).

Trotter Andrew 2007) states that allowing outside laptops onto the school network increases the risk of the spread of computer viruses and hacker attacks. He further indicates that wireless technologies users are now starting to upgrade the routers and hubs that create the wireless "hot spots," or areas where the wireless network can be accessed, from the $803.11 \mathrm{~b}$ standard, which moves data at a maximum 11 megabytes per second, to $803.11 \mathrm{~g}$, at 56 megabytes per second often making the difference between jerky and smooth motion for a streaming video. Such an upgrade becomes essential when schools have more than a few laptops operating in the same area, whether because of students' use of classroom laptop sets on carts or as part of a one-to-one laptop program. Trotter (2007) also indicates that another problem of wireless is that of the radio spectrum used by both the "b" and "g" versions which can be interfered by cell phones, microwaves, and other devices. Speed plays a factor when there are several students competing for the same website and the broadband width is not enough. The use of wireless devices in classroom can be a challenge for faculty trying to get the attention of students to a particular lecture when the students are engaged in the World Wide Web. However, one of the biggest challenges of wireless technologies in classroom is the problem of security. With more data and information transmitting frequently through the airwave, makes transmission of data easily accessible by hackers and intruders. Therefore, there is a need for security software updates to protect end-users from viruses and hackers.

Higher education can better teach tomorrow's digitally literate workforce. Online information, resources and learning tools are more readily available to students with wireless access to the internet; they can collaborate and share information with teachers and fellow students from anywhere at anytime. It is easier to install, no plug-ins, less clutter of wires, and is less expensive to maintain. With wireless technologies in the classroom, it is possible for students to have an interactive experience of learning even though they are not physically in the same location, they still can be seen and heard and participate into the lecture. Providing affordable network services to under-served families helps address socio-economic gaps. Redmond Wash (2003) stated that college students that own personal computers currently 87 percent has consistently increased from 75 percent three years ago, according to the semiannual student monitor survey. Gina LaGuardia, editor-in-chief of College Bound Teen Magazine also stated that "to succeed in college, students need every advantage, and PC ownership is one of the biggest, and that students should rely on their PCs more than ever before, particularly now that wireless networks provide the freedom and flexibility to access information on campus in many places. Wireless devices can enhance students and faculty creativity, they can use it to solve realistic problem-solving and share their work among their follow students. Special needs students can connect and express their thoughts and ideas with fellow classmates in the classroom.

\section{METHOD OF ANALYSIS}

During summer and fall semester 2007, students, faculty, and administrators in business school were surveyed using face-to-face and electronic means. A total of 300 respondents completed the questionnaires and the responses were analyzed. Questions assessed the level of importance that should be placed on wireless technologies in classroom and the perception of students and faculty regarding the effectiveness of wireless technologies in classroom. A simple statistical analysis was performed to determine the level of importance that should be placed in improving the effectiveness of teaching and learning performance with the incorporation of wireless technologies.

\section{PAPER QUESTIONS}

The ten questions below were to address the perception and relationship of wireless technologies and student's learning performance.

1. Do you have a wireless technology?

2. What type of wireless technologies? 
3. How important are wireless devices in enhancing students/faculty learning or teaching on and off the classroom?

4. What is the attitude of students/faculty toward wireless devices requirement in classroom?

5. How important will the campus-wide wireless technologies affect the student's decision to take online courses at the university?

6. What type of financial assistance will the students and faculty need to purchase wireless devices for classroom learning?

7. How involved will the faculty considered to be in the implementation of wireless devices in classroom?

8. How committed should the administrators considered to be in the implementation of wireless devices in classroom?

9. Will the implementation of wireless technologies in all classrooms improve the perceived effectiveness of teaching and learning performance?

10. Will there be a significant, positive relationship between the perceived effectiveness of wireless technologies in classroom and the importance placed on student learning performance?

A simple statistical analysis of the survey responses in percentages was performed to evaluate the level of importance placed and the relationship of wireless devices in classroom to faculty and student's performance in teaching and learning.

\section{PRESENTATION OF DATA}

The first question posed was "Do you have any wireless technologies for learning and teaching purposes?

Table 1: Ownership of Wireless Technologies

\begin{tabular}{|c|c|c|}
\hline Description & \# of Respondents & Percent \\
\hline Yes & 200 & $67 \%$ \\
\hline No & 100 & $33 \%$ \\
\hline Total & 300 & $100 \%$ \\
\hline
\end{tabular}

Sixty seven percent of the respondents stated that they have wireless technology devices for their teaching and learning productivity, while thirty three percent responded no. This indicate that there is an absolute need to encourage students and faculty to own or lease in order to adapt to the emerging wireless technologies in classroom for active learning and teaching at predominantly historical black colleges and university.

Table 2: Types of Wireless Devices

\begin{tabular}{|c|c|c|}
\hline \multicolumn{2}{|c|}{ What type of wireless technologies do you have? } \\
\hline PDAs & \# of Respondents & Percent \\
\hline & 100 & $33 \%$ \\
\hline Cell Phones & & $50 \%$ \\
\hline Wireless Laptop Computer & 150 & $17 \%$ \\
\hline Total & 50 & $100 \%$ \\
\hline
\end{tabular}

The students and faculty were asked the types of wireless devices that they have. The table indicates that students and faculty have more cell phones and PDAs than wireless laptop computer for usage. 
Table 3: Importance of Wireless Technologies in enhancing students/faculty learning and teaching

\begin{tabular}{|c|c|c|}
\hline \multicolumn{2}{|c|}{ Importance of Wireless Technologies in enhancing students/faculty learning or teaching } \\
\hline & \# of Respondents & Percent \\
\hline Very important & 200 & $67 \%$ \\
\hline Important & 50 & $17 \%$ \\
\hline Moderately important & 10 & $3 \%$ \\
\hline Slightly important & 15 & $8 \%$ \\
\hline Not at all important & 25 & $100 \%$ \\
\hline Total & 300 & $5 \%$ \\
\hline
\end{tabular}

Table 3 questions ask how important wireless technologies are in enhancing students/faculty learning and teaching. About sixty seven percent of students/faculty responded very important, and seventeen percent responded important while eight percent indicated not at all important. These eight percent might still be comfortable with the desktop approach or still using the dial-up approach.

Table 4: Attitude of Student/Faculty toward Wireless Technologies in Classroom

\begin{tabular}{|c|c|c|}
\hline \multicolumn{2}{|c|}{ Attitude of students/faculty toward wireless devices in classroom } \\
\hline & \# of Respondents & Percent \\
\hline & & $73 \%$ \\
\hline Strongly positive & 220 & $5 \%$ \\
\hline Somewhat positive & 15 & $2 \%$ \\
\hline Neutral & 5 & $13 \%$ \\
\hline Strongly negative & 40 & $7 \%$ \\
\hline Somewhat negative & 20 & $100 \%$ \\
\hline Total & 300 & \\
\hline
\end{tabular}

There was a significant difference in the response of students and faculty based on the attitude toward wireless technologies in classrooms. Seventy three percent were strongly positive and five percent were somewhat positive while thirteen percent were strongly negative and also seven percent somewhat negative for wireless technologies.

Table 5: Campus-wide Wireless Technologies Affect the Student's Decision to take Online Courses at the University

\begin{tabular}{|c|c|c|}
\hline \multicolumn{2}{|c|}{ Campus-wide wireless technologies affect the student's decision to take online courses at the university } \\
\hline & \# of Respondents & Percent \\
\hline & & $77 \%$ \\
\hline Great deal of importance & 230 & $13 \%$ \\
\hline Much importance & 40 & $3 \%$ \\
\hline Moderate importance & 10 & $4 \%$ \\
\hline Relatively Little importance & 12 & $3 \%$ \\
\hline None or Almost no importance & 8 & $100 \%$ \\
\hline Total & 300 & \\
\hline
\end{tabular}

Table 5 measured the campus-wide wireless technologies and how important it will affect student's decision in taking online courses. About seventy seven respondents emphasized a great deal of importance and thirteen percent also indicated much importance, while four percent and three percent said relatively little importance and almost no importance. 
Table 6: Involvement of Faculty in the Implementation of Wireless Technologies in Classroom

\begin{tabular}{|c|c|c|}
\hline \multicolumn{2}{|c|}{ Involvement of faculty in the implementation of wireless technologies in classroom } \\
\hline & \# of Respondents & Percent \\
\hline Very Involved & 240 & $3 \%$ \\
\hline Considerably involved & 10 & $2 \%$ \\
\hline Moderately involved & 5 & $13 \%$ \\
\hline Slightly involved & 40 & $2 \%$ \\
\hline Not involved & 5 & $100 \%$ \\
\hline Total & 300 & \\
\hline
\end{tabular}

It was very interesting to note that eighty percent of the respondents emphasized that faculty must be very involved in the implementation of wireless technologies in classroom, since wireless is the way of communication in today's society.

Table 7: Commitment of Administrators in the Implementation of Wireless Technologies in the Classroom

\begin{tabular}{|c|c|c|}
\hline \multicolumn{2}{|c|}{ Commitment of administrators considered to be in the implementation of wireless technologies in classroom } \\
\hline & \# of Respondents & Percent \\
\hline Very committed & 255 & $5 \%$ \\
\hline Considerably committed & 15 & $3 \%$ \\
\hline Moderately committed & 8 & $1 \%$ \\
\hline Slightly committed & 2 & $7 \%$ \\
\hline Not committed & 20 & $100 \%$ \\
\hline Total & 300 & $5 \%$ \\
\hline
\end{tabular}

In table 7, the respondents were further questioned on the levels of commitment of administrators in the implementation of wireless technologies in the classroom. Precisely eighty five percent of the respondents agreed that administrators should be very committed in the implementation of wireless technologies in today's learning environment. In addition to a total of nine percent supporting that administrators should be considerably moderately, and slightly committed. A small seven percent also indicated that administrators should not be committed to wireless technologies in classroom.

Table 8: Implementation of Wireless Technologies in Classrooms and Its Improvement In Perceived Effectiveness of Teaching/Learning Performance

\begin{tabular}{|c|c|c|}
\hline \multicolumn{3}{|c|}{$\begin{array}{c}\text { Will Implementation of wireless technologies in classrooms improve } \\
\text { the perceived effectiveness of teaching/learning performance? }\end{array}$} \\
\hline & \# of Respondents & Percent \\
\hline Yes & 235 & $78 \%$ \\
\hline No & 65 & $22 \%$ \\
\hline Total & 300 & $100 \%$ \\
\hline
\end{tabular}

It was interesting to note the high percentage of seventy eight percent of respondents agreed and believe that implementation of wireless technologies in classrooms can improve the perceived effectiveness of teaching and learning performance of students and faculty. 
Table 9: Relationship between the Perceived Effectiveness of Wireless Technologies in Classrooms and the Importance Placed on Student Learning Performance

\begin{tabular}{|c|c|c|}
\hline \multicolumn{2}{|c|}{$\begin{array}{c}\text { Will there be a significant, positive relationship between the perceived effectiveness of wireless technologies in } \\
\text { classrooms and The importance placed on student learning performance? }\end{array}$} \\
\hline & \# of Respondents & $87 \%$ \\
\hline Strongly Agree & 262 & $13 \%$ \\
\hline Strongly disagree & 38 & $100 \%$ \\
\hline Total & 300 & 100 t \\
\hline
\end{tabular}

Finally, the respondents were asked the significance of the relationship between the perceived effectiveness and the importance that should be placed on student's learning performance with wireless technologies in classrooms. Eighty seven percent strongly agree that inclusion of wireless technologies in classrooms will definitely bring a positive effectiveness and efficiency to students learning performance and productivity by clicking to the classroom from anywhere and anytime in the world.

\section{CONCLUSIONS}

In conclusion, the opportunities of wireless technologies greatly outweigh the challenges. It is believed that using wireless technologies in classrooms not only improves teaching and learning but provides the accessibility of resources to students and teachers. The interactions among students outside and inside of the classrooms will be greatly amazed. It can no longer be doubted that wireless technologies offer a tremendous amount of potential and eliminates the academic isolation and other limitations associated with traditional learning at a distance. The move of wireless technologies away from standalone computers will be a great change and will likely affect students and faculty. Overall, students and faculty were positive to accept the transition of wireless technologies in all classrooms as opposed to traditional way of teaching and learning. The transition of wireless technologies in classrooms has absolutely increased while improving the number of students recruited and enrolled into many of the classes taught through distance learning (DL).

\section{REFERENCES}

1. Conover, Joel, Anatomy of IEEE 802.11b Wireless

2. Glen, B., Gina, B., Garofalo, J., and Harris, J. (2002). Grand Challenges: Preparing for the Technological Tipping Point. Retrieved on September 22, 2007 from www.iste.org/Content/NavigationMenu/Publication/LL/LLIssues/Volume_29_2001_2002_/May15/May_2 $\underline{002 . h t m}$

3. Hamblen M. (2000). Wireless technology presents new security challenges. ComputerWorld: Retrieved on September 22, 2007 from http://archives.cnn.com/2000/TECH/computing/09/07/wireless.risks.idg/index.html

4. $\quad$ Liu, Bob, IEEE Unable to Agree on 802.11g Standard

5. Merritt, R. (2003). Tools for the TEKS: Integrating Technology in the Classroom, Bluetooth readies Spec for 2, 10-Mbit/s data rates. Retrieved on October 1, 2007 from http://www.wtvi.com/ TEKS/02 03articles /wireless future.html

6. Sande, M. (2004). Campus Technology: How Do You Make a Good Thing Better? Syllabus Magazine: September 2004, Volume 18, No. 1 www.Syllabus.com

7. Trotter, A. (2007), Wireless Technologies Present New Set of Challenges. Education Week: http://www.edweek.org/ew/articles/2007/06/20/01sr_management.h01.html, retrieved on September 18, 2007.

8. Wash, R. (2003) Technology 101: Windows XP Expands Students' Potential. Helping Students Access Wireless Networks, Enjoy Digital Entertainment and Succeed Academically. Retrieved on October 1, 2007 from http://www.microsoft.com

9. Wesley, F.(2003). The Opportunities and Challenges of Wireless Computing. 
NOTES 